\title{
An hybrid control strategy design for Photovoltaic battery charger
}

\author{
Iliass Rkik ${ }^{1, *}$, Mohamed El khayat ${ }^{1,}$, Hafsa Hamidane $^{1,}$, Abdelali Ed-Dahhak ${ }^{1}$, Mohammed Guerbaoui ${ }^{1,}$, and Abdeslam \\ Lachhab $^{1,}$ \\ ${ }^{1}$ Modelling, Materials and Systems Control Team, Higher school of Technology, Moulay Ismail University of Meknes, Morocco.
}

\begin{abstract}
This work presents the design and the modelling of an improved lead acid Battery charger for solar photovoltaic applications. In this context, the control unit of the battery charger is composed of two intelligent controllers. In the first state, an MPPT controller based on an Adaptive neuro-fuzzy inference system (ANFIS) is used to extract the full maximum power provided by the PV array, in the second stage, the control unit switches to the regulator mode on the basis of a fuzzy logic control block that offers the three charging stages according to DIN 41773 standard for lead-acid battery. In order to demonstrate the performance of the ANFIS controller, this paper presents also a comparison of several MPPT techniques for solar PV applications.
\end{abstract}

\section{Introduction}

In recent decades, photovoltaic (PV) systems have become a vital source of energy for a wide range of applications. They are the ideal options for many modest electrical energy demanding systems in distant regions where the grid source or tiny alternator are insufficient [1]. Solar energy's inconsistency can be solved by using storage devices. As a result, a constant and uninterruptible energy supply can be guaranteed. In renewable energy systems, the battery is the most efficient long-term electrical energy storage equipment. Lead-Acid(Le-A) batteries are the most widely installed storage devices in the PV applications thanks to its confirmed stability, excellent performance in various sizes, and cheaper cost.

Several maximum power point tracking (MPPT) methods have been implemented in the literature, and they may be classified into the following categories[2],[3]: classical MPPT methods, MPPT methods based on linear and non-linear controllers, as well as MPPT strategies based on Artificial Intelligence (AI). The conventional Perturb and Observe (P \& O) strategy[4], incremental conductance (IncC), adaptative neuro-fuzzy inference system (ANFIS), and neural network [5],[6] strategies are some of the most widely used MPPT techniques. The ANFIS controllerbased MPPT approach has attracted a large number of researchers[7],[8],[9].

Furthermore, it has been confirmed that the adaptive neuro-fuzzy inference system control method MPPT exceeds conventional MPPT methods in terms of resilience and efficiency under varying weather circumstances[10].

As a bridge between the Pv panel and the battery bank, an MPPT method needs a dc-dc converter. The MPPT's role is to control the converter's duty cycle and fit the voltage and current of the PV array's maximum power under

*e-mail: rkik.iliass@gmail.com/iliass.rkik@edu.umi.ac.ma such A meteorological conditions by adjusting the duty cycle of the converter [11].

Furthermore, the management of the converter as a battery charger is frequently overlooked, despite the fact that lead acid batteries need an accurate control of their charging operations to avoid battery damage. This is especially important in isolated PV systems, where the battery bank is unquestionably one of the costlier components.

According to the literature, many methods and strategies for charging batteries have been developed, including constant current, constant voltage, and on-off, among others; nevertheless, these techniques often result in the battery not being completely charged. On the other hand, most lead acid battery producers suggest that the three stages charging technique according to the DIN41773 standard is the best and most effective approach to restore the battery's full capacity and prolong the battery's lifespan.

\section{Methodology}

This paper provides in this regard, an improved control approach for a DC-DC Buck converter utilized as an efficient lead-acid battery charger for stand-alone solar PVBattery system [12]. The proposed control technique adjusts the DC-DC converter's duty cycle with two main goals: first, achieving the maximum power provided by the solar PV array through the implication of the ANFIS MPPT Technique, second, increasing the lifespan of the lead acif battery by employing a fuzzy logic controller for the battery load in three stages charging process. The schematic representation of a standalone PV-based MPPT battery charger closed loop controller is shown in the figure 1. The simulation of the general system is developed in Matlab/Simulink ${ }^{T M}$. 


\section{System design}

\subsection{PV Modeling}

An ideal solar PV cell is fundamentally constituted of a $\mathrm{PN}$ semiconductor junction that converts light energy into electricity. A current source with a diode linked in parallel can be used to present a solar cell. In a practical system, however, both the series and shunt resistances have fixed values and should be taken into account as presented in the figure 2 [13]. The PV cell's produced current is determined by the following formula:

$$
I_{p v}=I_{p h}-\left(\frac{V_{p v}+R_{s} * I}{R_{p}}\right)-I_{o}\left(e^{\frac{q\left(R_{s} * I+V_{d}\right)}{n \cdot k \cdot T}}-1\right)
$$

By neglecting the shunt resistance, the following expression can be calculated.

$$
V_{p v}=\left[\frac{A K T}{q} \ln \left(\frac{I_{0}-I+I_{s c}}{I_{0}}\right)\right]-I * R_{s}
$$

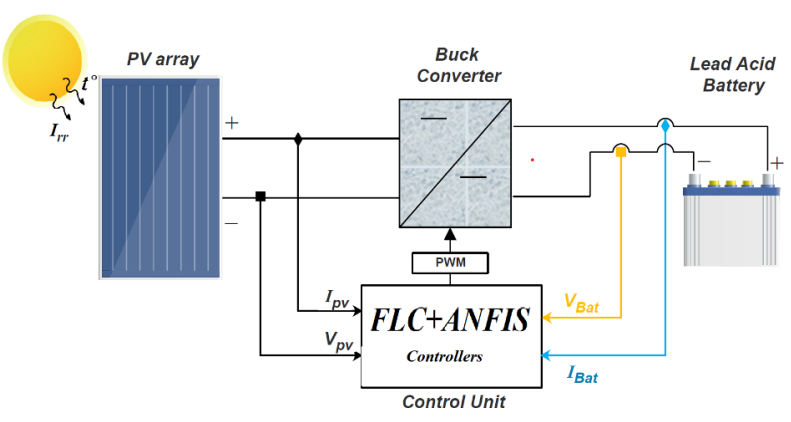

Figure 1. PV battery control system schematic

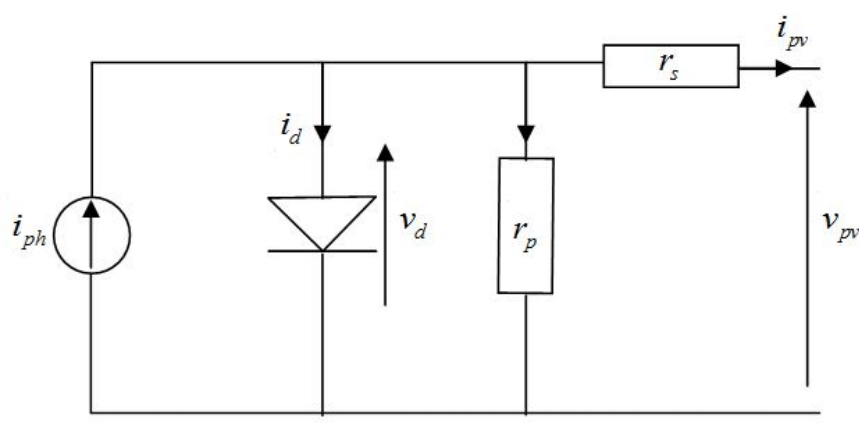

Figure 2. Photovoltaic Cell

The Photovoltaic system acts as a power supply when exposed to light. The PV array is always an arrangement of series/parallel of solar panels. The PV array utilized in this study is made up of 8 Shenzhen Sunshine modules (SY-270W) linked in series. The parameters of the used PV-panel are given in Table 1. The design for the industrial employed panel has been created in order to obtain more realistic simulation scenarios.
Table 1. SY-270W panel's parameters

\begin{tabular}{|l|c|r|}
\hline PV Data & Unit & Value \\
\hline Maximum power & $\mathrm{W}$ & 270 \\
Current at the MPP & $\mathrm{A}$ & $7.44 \mathrm{~A}$ \\
Voltage at the MPP & $\mathrm{V}$ & 36.28 \\
Open-Circuit Voltage & $\mathrm{V}$ & 43.63 \\
Short-Circuit Current & $\mathrm{A}$ & 7.96 \\
\hline
\end{tabular}

\subsection{DC/DC Buck converter Modeling}

The DC-DC buck converter was selected in this study for the purpose of adjusting the input voltage into the desired low Le-acid battery voltage[14]. The figure 3 corresponds to the average model of the buck converter based essentially of the internal and output capacitors Cin and Co. S and $\mathrm{L}_{b}$ are the controlled MOSFET and the inductance, where the input/output voltages are respectively Vin \& Vout. The figure 4 presents the equivalent circuit of the converter where the switch $\mathrm{S}$ is on or off. The buck parameters are calculated as follow:

$$
\begin{gathered}
V_{\text {out }}=V_{\text {in }} \times D \\
L_{b}=V_{\text {out }} \frac{1-D}{\Delta I \times f} \\
C=V_{\text {out }} \frac{1-D}{8 f \times L_{b} \times \Delta V_{\text {out }}}
\end{gathered}
$$

Ripples in the output voltage and the amount current ripples are respectively called $\Delta I$ and $\Delta V_{\text {out }}$.

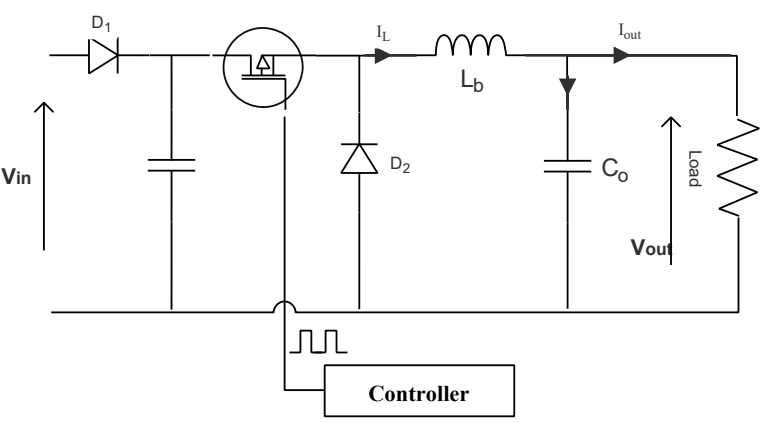

Figure 3. Buck design

\subsection{Le-Acid Battery design}

Because of their proven reliability, excellent performance, and availability in a variety of sizes, as well as their cheaper price, Lead-Acid batteries are the most frequently used storage equipment in the PV systems [15],[16]. A parallel resistance and capacitance $\mathrm{R} 1 / / \mathrm{C} 1$ connected to an internal resistance $R_{2}$ in series with a voltage source are the fundamental element of the Le-A battery circuit. Figure 5 shows the Le-A battery's associated circuit architecture. 


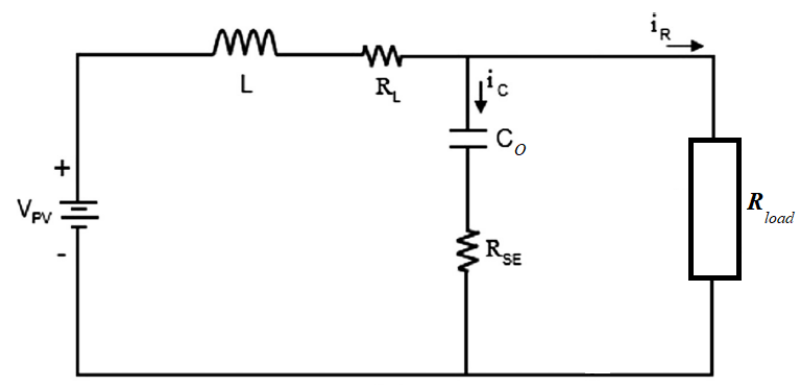

(a)

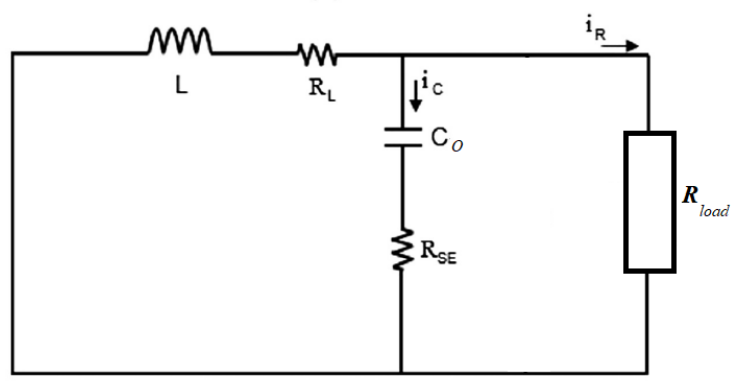

(b)

Figure 4. Buck design (a) Switch on (b) Switch off

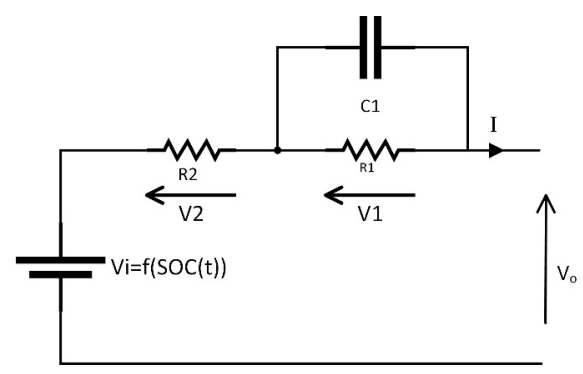

Figure 5. Le-Acid battery model

\section{Control strategy}

The enhanced control management introduced in this study is presented in this part. The main aim of this technique is presented in the flowchart below in the figure 6. This technique is based on the combination of two intelligent techniques which are the ANFIS algorithm and the Fuzzy Logic control(FLC) technique.

\subsection{Battery charging process}

To accomplish a steady, full, and fast Le-A battery charging process, a control design approach must be used. The charge controller suggested in this article is based on the DIN 41773 standard, which includes three charging phases, as illustrated in the figure 7 : bulk, absorption, and float. The bulk charge is the initial step, during which the effective ANFIS controller acts to extract the most power from the PV panel, which allows the charging of the LeadAcid battery through a constant current up to 80 percent

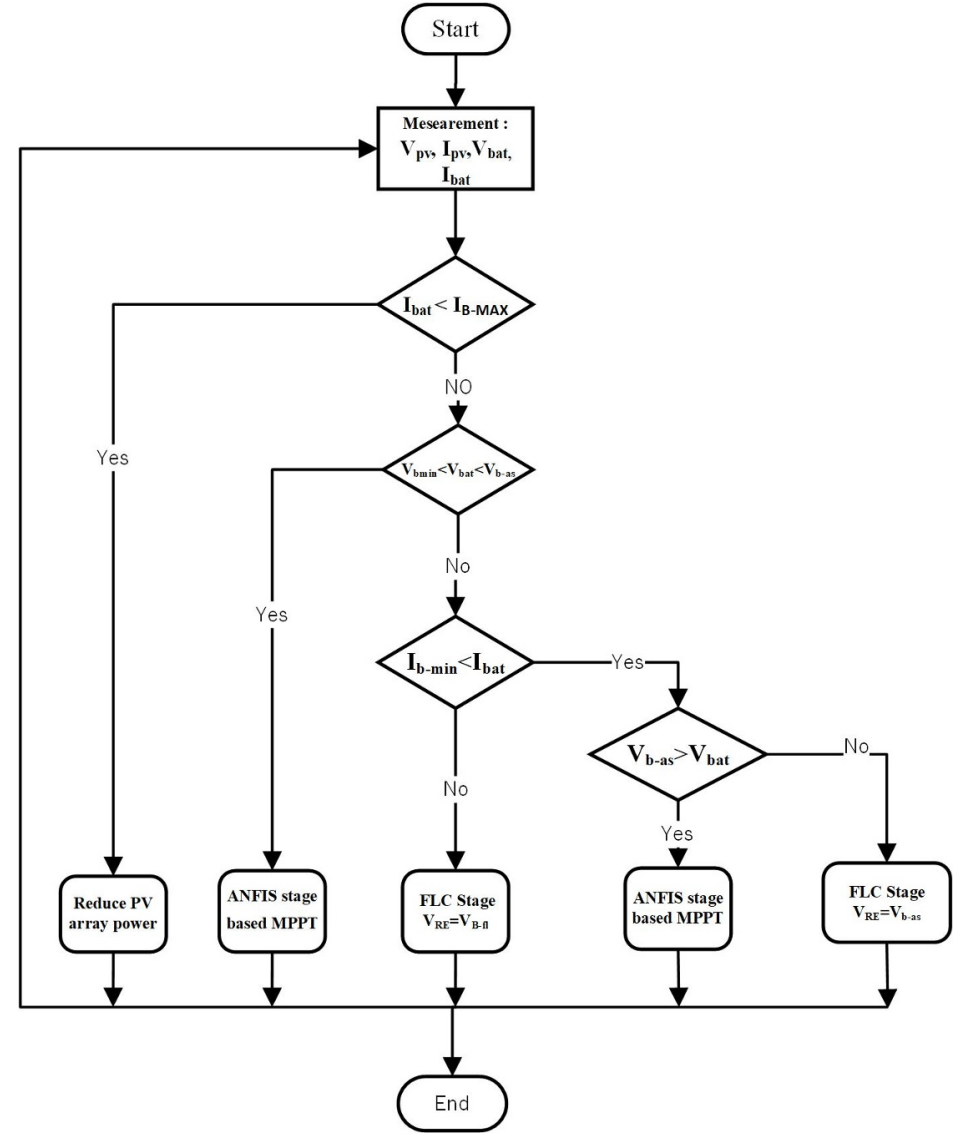

Figure 6. Flowchart of the improved PV-Battery charging technique

of the SOC. The provided current is limited to the allowed maximum charging current $I_{(B M A X)}$ during the bulk process to avoid early battery deterioration and excessive heating. The battery voltage begins to approach the absorption voltage $V_{(\text {bas })}$; to avoid over-voltage, the second stage which presents the FLC controller is activated in this phase (absorption) to regulate the battery voltage at this point $V_{(\text {bas })}$. At this stage, the battery power is usually recovered to approximately $90 \%$. The constructor is always in charge of determining the complete charge voltage. The charging current decreases in the absorption area until the battery is fully charged, with $I_{(\text {Battery })}=I_{(\text {Bmin })}$. When the battery arrived at $100 \%$ of its SoC, the voltage is reduced to its float voltage $V_{(b f l)}$ where this state is named the Float State. At this phase, the $V_{(b f l)}$ reference generates a neglected float current $I_{(b f l)}$ which is enough to compensate for self-discharge .

\subsection{Description of the ANFIS and FLC controllers}

\subsubsection{ANFIS stage based MPPT control}

The ANFIS model is divided into five levels, each one has a similar purpose [17]. The IF-THEN rule set, whose outputs are linear configurations of their inputs [18],[19]. The 


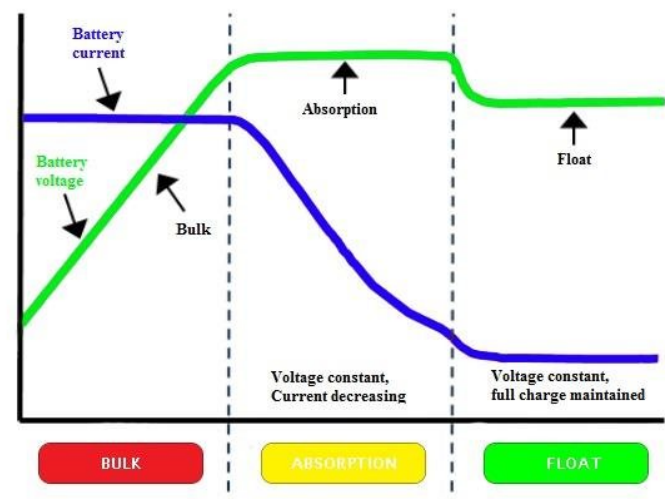

Figure 7. Three states charging process

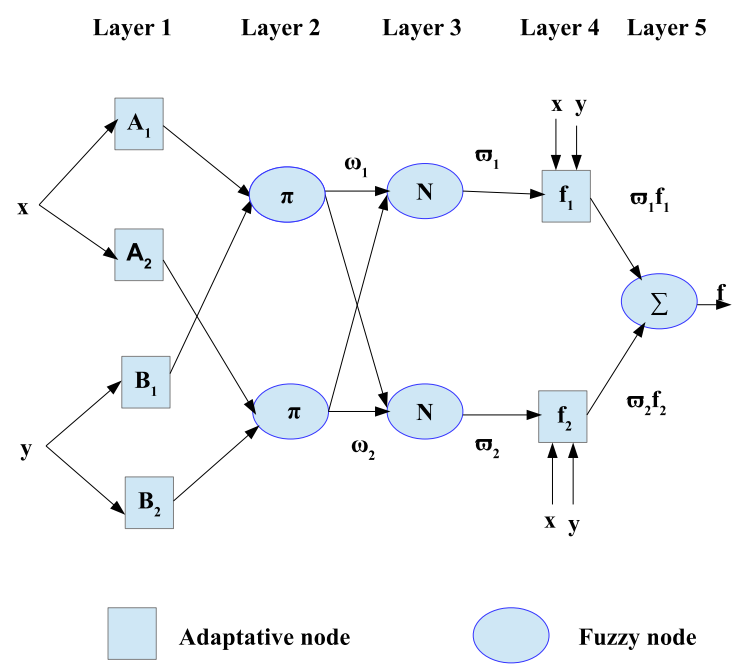

Figure 8. Design of five-layer ANFIS controller

figure 8 represents the architecture of the ANFIS configuration.

The first layer: is composed of membership functions, which are used to do the fuzzification operation, and each node is adaptive.

$$
O_{i}^{1}=\mu_{i A}(X)
$$

Where the input of the node is $\mathrm{X}$, and (Ai), (Bi) are a linguistic label connected with this node.

Layer 2 : This layer's nodes are fixed. A rule's firing strength is represented by each node output. The output of each Layer 2 node determines the rule base's firing strength, where the node function is defined as follows:

$$
O_{i}^{2}=W_{(i)}=\mu_{A i}(X) \cdot \mu_{B i}(X)
$$

Layer 3: This layer node is defined as a fixed node, and its result is computed by calculating the ratio of every node's value to the total of all nodes' values.

\begin{tabular}{|c|c|c|c|c|c|c|}
\hline & \multicolumn{5}{|c|}{$\zeta^{\prime}$} \\
\hline & & $\mathrm{N}, \mathrm{B}$ & $\mathrm{N}, \mathrm{M}$ & $\mathrm{ZE}$ & $\mathrm{P}, \mathrm{M}$ & $\mathrm{P}, \mathrm{B}$ \\
\hline \multirow{5}{*}{$\Delta \zeta^{\prime}$} & P,B & N,B & N,B & $\mathrm{N}, \mathrm{B}$ & $\mathrm{ZE}$ & $\mathrm{ZE}$ \\
\hline & $\mathrm{P}, \mathrm{M}$ & $\mathrm{N}, \mathrm{M}$ & $\mathrm{N}, \mathrm{M}$ & $\mathrm{N}, \mathrm{M}$ & $\mathrm{ZE}$ & $\mathrm{ZE}$ \\
\hline & $\overline{\mathrm{ZE}}$ & $\mathrm{P}, \mathrm{M}$ & $\mathrm{ZE}$ & $\mathrm{ZE}$ & $\mathrm{ZE}$ & $\mathrm{N}, \mathrm{M}$ \\
\hline & $\mathrm{N}, \mathrm{M}$ & $\mathrm{ZE}$ & $\mathrm{ZE}$ & $\mathrm{N}, \mathrm{M}$ & $\mathrm{P}, \mathrm{M}$ & $\mathrm{P}, \mathrm{M}$ \\
\hline & N,B & $\mathrm{ZE}$ & $\mathrm{ZE}$ & $\mathrm{P}, \mathrm{B}$ & $\mathrm{P}, \mathrm{B}$ & $\mathrm{P}, \mathrm{B}$ \\
\hline
\end{tabular}

Table 2. Voltage controller fuzzy rules.

for $i=1 \& 2$

$$
O_{i}^{3}=\frac{W_{i}}{\sum_{1}^{2} W_{i}}
$$

Layer 4: An adaptive node is a kind of layer node. The following equation represents the form of this node :

$$
O_{i}^{4}=\hat{W}_{i}\left(r_{i}+q_{i} b+p_{i} a\right)
$$

Where $\left(r_{i}, q_{i}, p_{i}\right)$ are the resulted parameters of the network.

Layer 5: The resulting output is provided by the sum of the preceding outputs in the final layer.

$$
O_{i}^{5}=\sum_{i=1} \hat{W}_{i} f_{i}
$$

\subsubsection{FLC stage based voltage control}

The second stage of the controller is the fuzzy logic unit called (FLC2), which employs as inputs the error $\zeta^{\prime}$ and the error change $\Delta \zeta^{\prime}$ of the battery's voltage as indicated in the following equations. The fuzzy memberships rules are presented in detail in the table 2 . It regulates the voltage in the output of the battery with the typical voltage of the power converter.

$$
\begin{gathered}
\zeta_{(n)}^{\prime}=V_{L}(n)-V_{B}(n) \\
\Delta \zeta^{\prime}{ }_{(n)}=\zeta^{\prime}{ }_{(n)}-\zeta^{\prime}{ }_{(n-1)} \\
\Delta D^{\prime}{ }_{n+1}=F L C_{2}\left[\zeta^{\prime}(n)\right]
\end{gathered}
$$

Where $\mathrm{V}_{L}$ is the battery voltage required, $\Delta D^{\prime}{ }_{n+1}$ is the FLC controller's output .

\section{Results and discussion}

The developed model is simulated in MATLAB/Simulink ${ }^{T M}$ software. On the investigated system, several simulations are performed. The PV array is made up of eight $270 \mathrm{~W}$ SY-270W PV panels connected in series. This part presents the simulation of the whole system. Firstly, The ANFIS MPPT controller is investigated under a sudden change in the solar irradiation as seen in the profile shown in the figure 9.

The developed model is tested and compares with two other techniques. A comparative evaluation between the three techniques P\&O, FLC, and ANFIS is carried out in 
Table 3. Performance analysis of the different MPPT techniques

\begin{tabular}{|c|l|l|l|}
\cline { 2 - 4 } \multicolumn{1}{c|}{} & P and O & ANFIS & InCond \\
\hline$\tau$ Rise time(s) & 0.188 & 0.118 & 0.202 \\
\hline Power ripples(w) & 0.8 & 0.056 & 0.62 \\
\hline Efficiency \% & 99.81 & 99.93 & 99.88 \\
\hline
\end{tabular}

order to see the effectiveness of the ANFIS method. The above equation is used to calculate the efficiency of the three tested controller.

$$
\eta=\int_{0}^{t} P_{\text {array }} \frac{1}{\int_{0}^{t} P^{\prime}{ }_{M P P T}} \times 100
$$

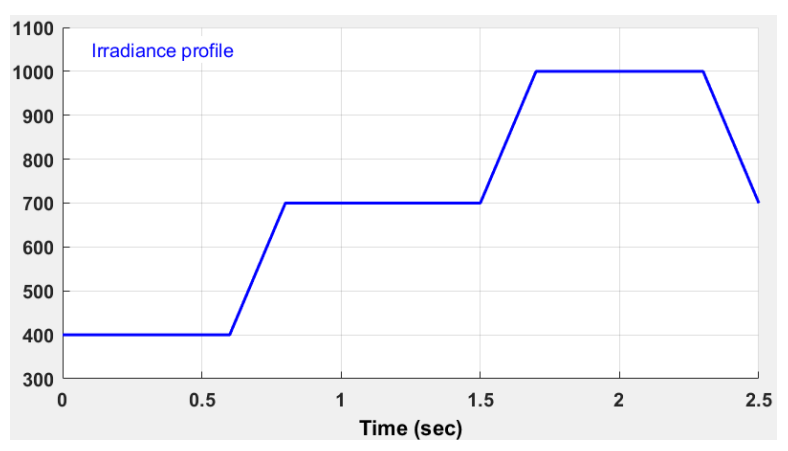

Figure 9. Irradiance profile

Figure 10 depicts the performance of the comparative MPPT methods for each irradiance condition, whereas Table 3 highlights the findings for the various controllers. When compared to other MPPT controllers, the ANFISMPPT provides a better outcome in terms of dynamic response and output ripples.

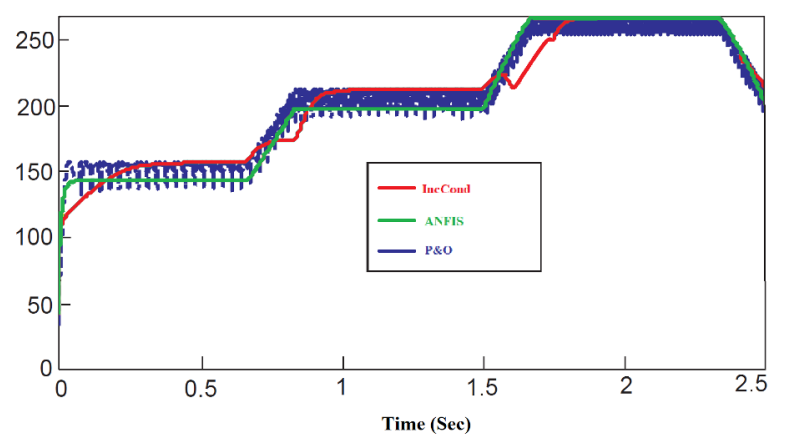

Figure 10. Power extracted of the SY-270W with different controller

The output of the battery charge regulator is shown by progressively charging the battery via the bulk stage, absorption stage, and float phase. The three-stage charging levels of the Le-A battery are clearly seen in the figure 11 . the used battery bank is an $24 \mathrm{~V} / 50 \mathrm{AH}$ battery, it consists of two $12 \mathrm{~V}$ batteries associated in series, where the simulation is conducted via a standard test conditions.

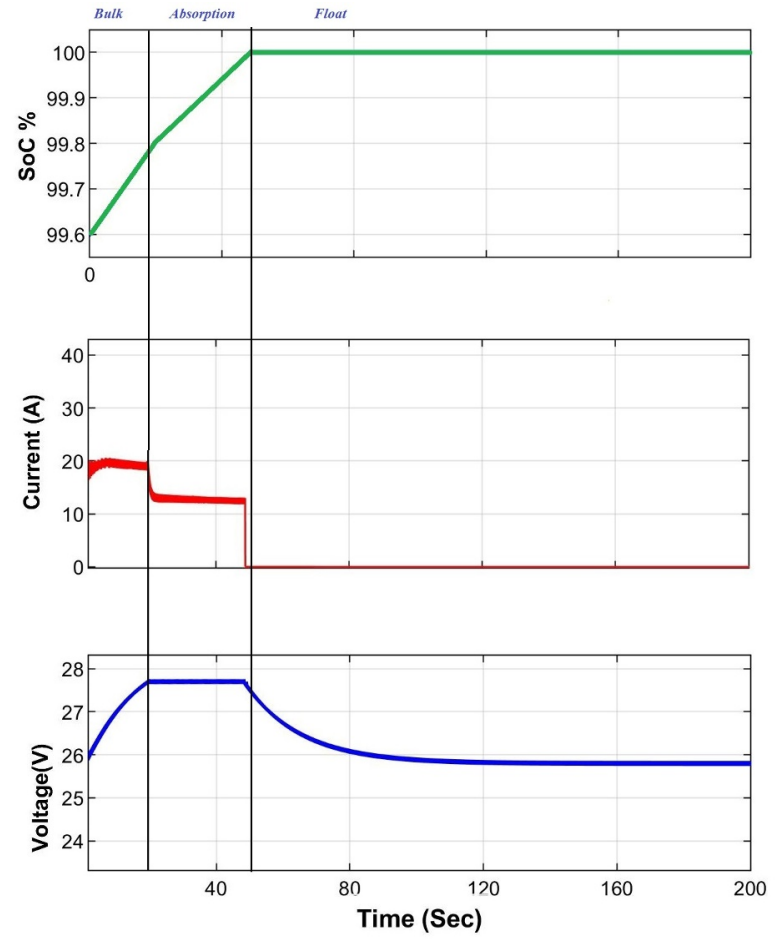

Figure 11. The Le-A Battery performance of the second test

\section{Conclusion}

A smart lead acid battery charger controller for PV/battery applications is presented in this paper. The suggested technique allows the system to perform in ideal circumstances according to the three stages charging technique. Therefore, the control strategy developped is an hybrid controller (ANFIS based MPPT and the FLC based voltage regulator). The results of the current study demonstrate that the ANFIS technique provides a better performance compared to the traditional $\mathrm{P} \& \mathrm{O}$ and IncCon methods in terms of efficiency and rising time, while the second fuzzy controller FLC2 acts as a voltage charge regulator to guarantee the maintaining of the voltage across the Le-A battery, thus, verify automatically the DIN 41773 standard. The proposed control method offers the advantages of recovering the maximum power from the PV array, minimising battery damage caused by changing MPPT voltage, and extending the battery life. The experimental implementation of the suggested control strategy will be considered in the future research.

\section{References}

[1] I. Rkik, M. El, H. Hamidane, A. Ed-dahhak, and M. Guerbaoui, "An intelligent lead-acid battery closedloop charger using a combined fuzzy controller for PV applications," vol. 01033, pp. 1-7, 2021.

[2] T. Esram, P. Chapman, "Comparison of Photovoltaic Array Maximum Power Point Tracking Techniques", IEEE Transactions on Energy Conversion, 22, 439-449 (2007). 
[3] N. A. Kamarzaman, C.W. Tan, "A Comprehensive Review of Maximum Power Point Tracking Algorithms for Photovoltaic Systems", Renewable and Sustainable Energy Reviews, 37, 585-598 (2014).

[4] M. Salimi, "Practical implementation of the Lyapunov based nonlinear controller in DC-DC boost converter for MPPT of the PV systems," Sol Energy, vol. 173, no. February, pp. 246-255, (2018).

[5] A. Alice Hepzibah and K. Premkumar, "ANFIS current-voltage controlled MPPT algorithm for solar powered brushless DC motor based water pump," Electr Eng, vol. 102, no. 1, pp. 421-435, (2020).

[6] D. P. Hohm and M. E. Ropp, "Comparative Study of Maximum Power Point Tracking Algorithms", Progress in Photovoltaics: Research and Applications, vol. 11, pp. 47-62, (2002)

[7] M. R. Rezoug, R. Chenni, and D. Taibi, "Fuzzy logicbased perturb and observe algorithm with variable step of a reference voltage for solar permanent magnet synchronous motor drive system fed by direct-connected photovoltaic array," Energies, vol. 11, no. 2, (2018)

[8] S. Marhraoui, "Fuzzy Logic-Integral Backstepping Control for PV Grid-Connected System with Energy Storage Management," Int J Intell Eng Syst, vol. 13, no. 3, (2020).

[9] K.V.Hari Prasad, CH.Uma Maheswar Rao," Design And Simulation Of A Fuzzy Logic Controller For Buck \& Boost Converters", International Journal of Advanced Technology \& Engineering Research, (2012).

[10] B. Bendib, F. Krim, H. Belmili, M. F. Almi, and S. Boulouma, "Advanced fuzzy MPPT controller for a stand-alone PV system,” Energy Procedia, vol. 50, pp. 383-392, (2014).

[11] M.A. Hasan, S.K.Parida, "An Overview of solar photovoltaic panel modeling based on analytical and experimental viewpoint". Renewable and Sustainable Energy Reviews, Vol. 60, pp. 75-83, (2016).

[12] R. K. Singh, A. Kumar, and B. K. Naick, "Optimised Solar Power Fed Induction Motor Drive for Wa- ter Pumping Application Along with Load," iEECON 2018 - 6th Int Electr Eng Congr, pp. 1-4, (2018)

[13] N. Yildiran and E. Tacer, "Identification of photovoltaic cell single diode discrete model parameters based on datasheet values," Sol Energy, vol. 127, pp. 175-183,(2016).

[14] R. Patil, and A. Harsha "Comparitive analysis of fuzzy based MPPT for buck and boost converter topologies for PV application." 2017 International Conference On Smart Technologies For Smart Nation (SmartTechCon). IEEE, (2017).

[15] A. Selmani, A. Ed-Dahhak, M. Outanoute, A. Lachhab, M. Guerbaoui, and B. Bouchikhi, "Performance evaluation of modelling and simulation of lead acid batteries for photovoltaic applications,' Int. J. Power Electron. Drive Syst., vol. 7, no. 2, pp. 472-480, (2016).

[16] J. Meng, D. I. Stroe,M. Ricco, G. Luo and R. Teodorescu, "A simplified model-based state-of-charge estimation approach for lithium-ion battery with dynamic linear model." IEEE Transactions on Industrial Electronics 66.10 (2018).

[17] H. Oubehar, M. El Khayat, I. Rkik, A. Ed-Dahhak, M. E. H. Archidi, and A. Lachhab, "Intelligent control for an experimental greenhouse climate based on anfis technology," International Journal of Advanced Trends in Computer Science and Engineering, vol. 9, no. 1.5 Special Issue, pp. 84-90, 2020

[18] H Hamidane, S. El Faiz, , I. Rkik, M. El Khayat, M. Guerbaoui, A. , Ed-Dhhak, and A. Lachhab, "Application analysis of ANFIS strategy for greenhouse climate parameters prediction: Internal temperature and internal relative humidity case of study," vol. 01041, pp. $1-7,2021$.

[19] M. Guerbaoui, A. Ed-Dahhak,Y. ElAfou, A.Lachhab,L. Belkoura, and B. Bouchikhi. "Implementation of direct fuzzy controller in greenhouse based on labview." International journal of electrical and electronics engineering studies, (2013) 